\title{
Vocational Schools and Regional Development in China
}

\author{
*Tam Bang Vu, Eric Iksoon Im \\ College of Business and Economics University of Hawaii-Hilo, Hilo, Hawaii, USA \\ *tamv@hawaii.edu
}

\begin{abstract}
This paper investigates the different impacts of vocational schools and universities on regional development in China. To account for a possible two-way causality between education and economic development, a system of supply and demand equations is introduced. The results show that vocational education has higher impact on regional development than university education in China. Concerning the reverse causality, the paper finds that effect of regional development on university education is higher than its effect on vocational school education.
\end{abstract}

Keywords: Regional development, vocational schools, universities, two-way causality.

\section{Introduction}

University education has been valued much higher than vocational education in China. Households strive to send their children to university, causing vocational schools to take a back seat in the nation's educational system. Influenced by this preferable mode of education, existing literature on the relationship between economic development and education in China has focused on growth of real GDP and three major levels of education, meaning primary, secondary, and college education. None of the papers investigates the different effects between vocational education and college education. Recently, due to the global economic recession, there are concerns among scholars that there is a surplus of university graduates whereas there is a shortage of vocational school graduates to fill the market demand for skill workers. This phenomenon increases unemployment, which is already very high for many countries. Although China enjoys strong economic growth during 2008-2009, the prospect for the next five years might be different, as demands for China's exports go down, causing job losses in China. Hence, more vocational graduates might help increase employment in China as well.

Now, there is no theoretical or empirical evidence that vocational school education affects regional development less than college education. Moreover, there is also no evidence that regional development does not affect the accumulations of human capital at the regional level. Additionally, none of the papers investigates the two-way causality between these two modes of education and regional development using data on regional outputs per worker for each sector of the economy. This paper aims to contribute to the existing literature on China's economy by filling these gaps in current research. An econometric model is introduced to account for the possible two-way causality between education and regional development. A combination of the System Generalized Method of Moments (SGMM) and Fixed Effect Three Stage Least Squares (FE3SLS) procedures is performed in order to control for lagged dependent variables and improve the efficiency of the estimators. The results show that vocational education helps regional development in China more than university education does. On the reverse causality, regional development results in more enrollments at universities than at vocational schools. Section 2 of this paper provides a review of the existing literature. Section 3 analyzes methodology and data. Section 4 reports the results and discussions. Section 5 concludes.

\section{Literature Review}

Several papers investigate the effects of education on per capita income. Using OLS on two singleequation estimations for cross sectional data of 81 to 93 countries, Bils and Klenow (2000) find that education only has a very weak effect on GDP per capita, but this GDP increase in turn has a positive effect on school enrollments. Hojo (2003) uses the country-specific residual from the regression by Caselli et al. (1996) as a proxy for productivity. Employing the GMM procedure introduced by Arellano and Bond (1991) on a single equation for cross sectional data of 90 countries, he finds that education has positive effect on productivity. Since higher productivity is related to a higher GDP per capita as shown in Islam (1995), Hojo's results imply that education can indirectly affect GDP per capita through productivity 
improvement at national level. Since all aforementioned papers use single equation estimations, their coefficient estimates will be biased if a two-way causality between education and GDP per capita exists.

Kumar (2003) develops a model that addresses this problem. Employing the two stage least squares (2SLS) approach for a system of equations, he uses cross sectional data with 68 to 91 observations. In contrast to Bils and Klenow (2000) and in accordance with Hojo (2003), he finds that education clearly increases productivity growth, but this growth in turn has a negative effect on enrollments instead of a positive one as in Bils and Klenow. However, the 2SLQ estimations are only asymptotically consistent, so large sample sizes are called for instead of Kumar's 68 to 91 observation data sets at national level. Vu and Hammes (2007) addressed Kumar's problem by using larger panel data set and a more advanced econometric method of three stage least squares (3SLS). They find that the two-way causality are both positive. Concerning vocational education, Masson (2009) points out that the shortage of vocational school graduates cause unemployment to rise and even though may firms have unfilled positions due to lack of skilled workers. Using qualitative data analysis, Banerji at al (2010) show that skills and skill development acquired through vocational education is very important in reducing unemployment and increase productivity.

In an analysis of reform in vocational education, Jakubowski at al (2010) show that reform in vocational education for more than a decade has paid fruitful dividends in Poland. Specifically, to increase flexibility for students, Poland restructures its 8-year primary school system that was followed by early vocational tracking to a 9-year comprehensive structure and so allow for the one-year delay in tracking. The evaluation shows that would-be vocational school students improved their learning outcomes by almost a standard deviation, leading to a significant overall improvement. Regarding the case of China, existing research has pointed out that returns to schooling in China have dramatically risen during the last twenty years, from far below world averages to almost the same as in major market economies. Empirical results also show that education has positive effects on GDP growth and per capita income (Demuger 2001; and Chen and Feng 2000). Hua (2006) uses macroeconomic yearly data for 29 regions in China to investigate the direct effects of education on productivity, as evidence by technical efficiency changes, technical progress, and total factor productivity. Numbers of graduates from each level divided by population measures his data on education. His overall result is that the effects of secondary and primary education on productivity are either negative or insignificant, whereas that of college education is positive and significant. Hua also finds that the combined effect of all three levels of education is only weakly significant.

On the contrary, Fleisher at al (2006) estimate the effect of education on productivity using microeconomic yearly data at firm level from China. They divide workers into less-educated and highly educated ones. Their results show that education increases productivity at both levels with higher level of education has stronger effect than lower level of education. $\mathrm{Vu}(2009)$ investigates a possible two-way causality between real GDP per capita and secondary school enrollments and finds that each-way effect is positive for the case of China. None of the papers on China's education compares and contrasts impact of vocational education versus university education on regional development. This paper set out to fill this gap in literature on China's Economy.

\section{Methodology and Data}

This econometric model involves a system of two equations. The first is a supply equation based on an augmented Solow model, and the second is a demand for education equation:

$$
\begin{aligned}
& D E V_{i t}=\alpha_{1} E D U_{i t}+\sum_{j=1}^{n} \alpha_{j} C_{j t}+u_{i}+v_{t}+\varepsilon_{i t} \\
& E D U_{i t}=\beta_{1} D E V_{i t}+\sum_{k=1}^{m} \beta_{k} A_{k t}+w_{i}+z_{t}+\psi_{i t}
\end{aligned}
$$

Where $D E V$ is regional development as evidence by output per worker for either agricultural, or industrial sectors. $E D U$ is education and could be either vocational or university enrollment ratio to employed workers as the benchmark variable. $\mathrm{C}$ is a vector of control variables that might affect regional output per worker such as physical capital, infrastructure, exports, domestic trade, etc. A is a vector of auxiliary variables that might affect human capital accumulations such as per capita income, domestic interest rates (as an opportunity cost to education), private expenditures and public expenditures on education, etc. An 
alternative model for a possible two-way causality between regional income per capita and the aforementioned two modes of education is also introduced. In cross sectional data analysis, it is very difficult to find an instrumental variable (IV) for each equation in the system as discussed in Bils and Klenow (2000). In panel data analysis, it becomes easy because lagged dependent variables can be used as IVs. We use the SGMM approach by Blundel and Bond (1998) and Bond (2002) to control for the lagged dependent variables in the reduced forms. In this approach, the authors add the difference of the instrumental variable (IVs) to make them exogenous to the fixed effects. In order to build this while retaining the original GMM for the transformed equation, they design a system GMM (SGMM) estimator while left multiplying the original data by a transformation matrix, $Z_{+}^{*}=\left[\begin{array}{c}Z^{*} \\ I\end{array}\right]$, where $Z^{*}$ is the differenced matrix. Hence for individual $i$, the new data set is

$$
X_{i+}^{*}=\left[\begin{array}{c}
X_{i}^{*} \\
X_{i}
\end{array}\right], \quad Y_{i+}^{*}=\left[\begin{array}{c}
Y_{i}^{*} \\
Y_{i}
\end{array}\right]
$$

When an endogenous variable is close to a random walk, past changes are more predictive of current levels than past levels are of current changes, so the new instruments add extra controls to the original ones for models with lagged dependent variables. Hence, the Blundell-Bond (1998) approach effectively controls for autocorrelation and heteroskedasticity, provides consistent coefficient estimates, and performs more reliable tests for autocorrelations and over-identifying restrictions than the original GMM. The predicted values of the SGMM estimations are then used as IVs for the 3SLS estimations. Data for 30 regions - including 22 provinces, five autonomous regions, and three municipal cities - are from China Statistical Yearbooks for 1989-2009. Data for Tibet are not comprehensive and therefore are eliminated from the data set. Data for Chongqing were included into data for Sichuan before 1997, so we add data for Chonging to data for Sichuan during 1997-2009 as well. Data for 1989-1991 have missing observations. If one observation is missing for a three-year period, we average the two remaining data points. If two observations are missing for a three-year period, we took the remaining data point as the average of the three. There are still more missing observations, so we have an unbalanced panel.

We use accumulated investment in fixed assets by region as a proxy for physical capital, turnover volume of freight traffic as a proxy for infrastructure, and total retail sale of consumer goods as a proxy for trade. The ratio of GDP to population is used as a proxy for per capita income. Data on utilized foreign direct investment are merged with data on foreign other investment for 1993-1995 period. Hence, we sum up the two categories when they are listed separately to obtain data for foreign investment. These data are then accumulated to make a proxy for foreign capital. Data are converted into real values using the price indices and respective GDP deflators. Data on exports and imports are measured according to location of managing unit by region.

\section{Results and Discussion}

A preliminary simultaneous-equation estimation, which uses all available variables that might affect productivity and human capital, confirms our intuition of a possible two-way causality between productivity and human capital. This estimation and the subsequently preliminary estimations are carried out with time dummies to control for autocorrelation. We also employ the White correction for the standard heteroskedasticity. We follow a downward piece-wise approach to avoid omitted variables, starting with all available variables. We then perform Variance Inflation Factor tests (VIF) to eliminate variables with high multicolinearity. The remaining variables and their VIF are reported in Table 1 . We estimate the reduced form of the system using SGMM approach as discussed in methodology section:

$$
\begin{aligned}
& E D U_{i t}=\gamma_{0}+\gamma_{1} E D U_{i, t-1}+\sum_{j=1}^{n} \chi_{j} C_{j t}+\phi_{i t} \\
& I N D_{i t}=\kappa_{0}+\kappa_{1} I N D_{i, t-1}+\sum_{k=1}^{m} \eta_{k} A_{k t}+\theta_{i t}
\end{aligned}
$$


Table 1(a): VIF Tests for Multicolinearity: Model for Agricultural Output

First Equation. Dependent Variables: Output per Worker

\begin{tabular}{lll}
\hline Variable & VIF & $\mathbf{1 / V I F}$ \\
\hline Physical Capital & 4.08 & 0.2452 \\
Vocational Education & 3.52 & 0.2843 \\
Private Expenditures & 2.83 & 0.3531 \\
Infrastructure & 1.56 & 0.6432 \\
Initial Industrial Output per Capita & 1.22 & 0.8214 \\
Mean VIF & 2.64 & \\
\hline & & \\
Second Equation. Dependent Variable: & Vocational Education \\
\hline Private Expenditures & 3.68 & 0.2721 \\
Interest Rate & 3.65 & 0.2742 \\
Output per Worker & 2.23 & 0.4484 \\
Public Expenditures & 1.25 & 0.7402 \\
Mean VIF & 2.40 & \\
\hline
\end{tabular}

Table 1(b): VIF Tests for Multicolinearity: Model for Industrial Output

First Equation. Dependent Variable: Output per Worker

\begin{tabular}{lll}
\hline Variable & VIF & $\mathbf{1 / V I F}$ \\
\hline Vocational Education & 3.91 & 0.2555 \\
Telecommunication & 2.94 & 0.3397 \\
Infrastructure & 1.91 & 0.5226 \\
Initial Level of Industrialization & 1.14 & 0.8793 \\
Mean VIF & 2.48 & \\
\hline
\end{tabular}

\section{Second Equation. Dependent Variable: Vocational Education}

$\begin{array}{lll}\text { Telecommunication } & 3.05 & 0.3275 \\ \text { Private Expenditures } & 2.57 & 0.3884 \\ \text { Output per Worker } & 1.80 & 0.5552 \\ \text { Public Expenditures } & 1.33 & 0.7518 \\ \text { Mean VIF } & 2.1 & \end{array}$

Note: replacing vocational education with university education yields similar results.

Obtained the predicted value of $D E V$ and $E D U$ as instrument variables, we then estimate the structural system using fixed effect three stages least squared (FE3SLS):

$$
\begin{aligned}
& D E V_{i t}=\alpha_{1} E D U H A T_{i t}+\alpha_{2} C A P_{i t}+\alpha_{3} I N F R A_{i t}+\alpha_{4} I N I T_{i}+\alpha_{5} E_{X X N_{i t}}+u_{i}+v_{t}+\varepsilon_{i t} \\
& E D U_{i t}=\beta_{1} D E V H A T_{i t}+\beta_{2} E X P N_{i t}+\beta_{3} \beta_{4} P E X P N_{i t}+I N T_{i t}+w_{i}+z_{t}+\psi_{i t}
\end{aligned}
$$

Where EDUHAT and DEVHAT are the predicted values of EDU and DEV obtained from system (2) estimations, respectively. CAP is physical capital, INFRA is infrastructure, INIT is initial level of development measured by initial level of industrial output per person or initial level of industrialization, EXPN is private expenditures, PEXPN is public expenditures on education, and INT is real interest rate. The results, which are reported in Table 2, show that the vocational education has higher impact than university education on outputs per worker in both agricultural and industrial sectors. Table 2 reports results for agricultural sector. It shows that a rise in vocational school enrollment ratio causes output per worker to increase $20 \%$ more than the effect of university enrollments. All results are at least significant at $5 \%$ levels. In addition, the p-value for the $\mathrm{F}$ tests of the model specifications is at least statistically significant at $5 \%$ level.

Since output per worker is a measure of productivity, these results are in line with existing literature discussed in the previous sections with all papers pointing out that education increases productivity. Hence, the case of China is the same as the case in other countries. Concerning vocational education, the results provide quantitative evidence supporting qualitative data analyses, which reveal that vocational 
education, improves worker skills and productivity; in this case, it is an increase in labor productivity. Therefore, China's case also fits the worldwide scenario. Regarding the reverse causalities, we find that an increase in labor productivity raise school enrollments in both levels of education. These results also a support theoretical empirical result provided by Bils and Klenow (2000) but is in contrast to the case in Kumar (2003). Additionally, this paper reveals that an increase of agricultural output per worker raises university enrollments more than vocational school enrollments. Specifically, the same percentage of increase in agricultural output per worker raises university enrollments twice more than those of vocational schools. This result is our contribution to the existing literature. Regarding public expenditures on education, we also find an interesting result: the same percentage increase in public expenditures on education raises vocational enrollments twice as much as university enrollments.

Table 2: Estimations Results: Model for Agricultural Sector

Panel (2a): Dependent Variable: Agricultural Output per Worker

\begin{tabular}{lcccc}
\hline Variable & Vocational Schools & p-value & Universities & p-value \\
\hline School Enrollments & $.0498^{* *}$ & .003 & $.0443^{* *}$ & .000 \\
Physical Capital & $.3362^{* *}$ & .046 & $.3187^{* *}$ & .033 \\
Infrastructure & $1.274^{* *}$ & .001 & $.9503^{*}$ & .076 \\
Private Expenditures & $.0969^{* *}$ & .005 & $.1195^{* *}$ & .001 \\
Initial Level of Agricultural & & & .099 \\
Output per Worker & $-.0671^{*}$ & .007 & $-.0524^{*}$ & .723 \\
Root Mean Square Error & .8562 & & .8014 & .000 \\
Adjusted R-squared & .6260 & & 177 & .472 \\
p-value for the Model Significance: & .000 & & .452 & \\
Number of observations: & 173 & & .526 \\
p-value for White test: & .593 & & \\
p-value for the LM test: & .382 & & \\
p-value for RESET on omitted variables: & .483 & & \\
\hline
\end{tabular}

Panel (2b): Dependent Variable: School Enrollment Ratio

\begin{tabular}{|c|c|c|c|c|}
\hline Variable & ional Schools & p-value & Universities & p-value \\
\hline Agricultural Output per Worker & $1.868^{* *}$ & .003 & $3.684^{* *}$ & .008 \\
\hline Private Expenditures & $.1866^{*}$ & .069 & $.1987^{*}$ & .082 \\
\hline Interest Rate & $-.0024^{*}$ & .087 & $-.0019 *$ & .091 \\
\hline \multicolumn{5}{|l|}{ Public Expenditures } \\
\hline On Education & $5.913^{* *}$ & .004 & $2.428^{* *}$ & .047 \\
\hline Root Mean Square Error & 1.553 & & 1.845 & \\
\hline Adjusted R-squared & .8023 & & .7143 & \\
\hline p-value for the model significance: & .000 & & .000 & \\
\hline Number of observations: & 173 & & 177 & \\
\hline p-value for White test: & .527 & & .462 & \\
\hline p-value for the $\operatorname{AR}(1)$ : & .418 & & .516 & \\
\hline p-value for RESET on omitted variables: & .415 & & .625 & \\
\hline
\end{tabular}

Note: $^{*}$ and ${ }^{* *}$ denotes significant levels at $10 \%$ and $5 \%$, respectively.

Since none of the existing papers carries out a research on the public expenditures, this is also out new contribution to the existing literature on education and productivity in China. Table 3 reports the results for the industrial output per worker. It shows similar results, that is, the effect of the vocational education is higher than that of the university education on industrial output per worker, but a rise in output per worker send twice as much students to universities as to vocational schools. From these results, several implications are drawn. First, the vocational schools are a better mode of education than university education for China to promote regional development. Second, when economic development is improved, most parents want to send their children to universities, reflecting the cultural fact in China. Third, public expenditures on education are more efficient spent on vocational education than on university education. Finally, a policy implication is that efforts have to be made in term of extending information to the public and educators so that people gradually realize that vocational education is not only important to regional development but also help increases per capita income when output per capita and productivity rise. 


\section{Conclusion}

This paper shows that vocational schools are preferable mode of education for China. To speed up the regional development process, Chinese government might want to increase its supports to Chinese vocational schools to expand their facilities, faculty, and staffs so that they can attract and serve more students. The government can also provide more scholarships and grants to students, in the mean time offer tax credits to families that wish to send their children to vocational schools.

Table 3. Estimations Results: Model for Industrial Sector

Panel (3a): Dependent Variable: Industrial Output per Worker

\begin{tabular}{lccll}
\hline Variable & Vocational Schools & p-value & Universities & p-value \\
\hline School Enrollments & $.0614^{* *}$ & .008 & $.5024^{* *}$ & .024 \\
Physical Capital & $.3256^{* *}$ & .037 & .3302 & .009 \\
Infrastructure & $1.108^{*}$ & .068 & $1.243^{*}$ & .072 \\
Private Expenditures & $1.325^{* *}$ & .004 & $1.215^{* *}$ & .046 \\
Initial Level of Industrial & & & & \\
Output per Worker & $-.0745^{* *}$ & .023 & $-.6824^{* *}$ & .009 \\
& & & & \\
Root Mean Square Error & .7957 & & .6858 & \\
Adjusted R-squared & .6753 & & .7469 & \\
p-value for the model significance: & .000 & & .000 & \\
Number of observations: & 173 & & .486 & \\
p-value for White test: & .586 & & .602 & \\
p-value for LM test: & .425 & .473 & \\
p-value for RESET on omitted variables: & .526 & &
\end{tabular}

Panel (3b): Dependent Variable: Enrollment Ratio

\begin{tabular}{lllll}
\hline Variable & Vocational Schools & p-value & Universities & p-value \\
\hline Industrial Output per Worker & $1.523^{* *}$ & .006 & $4.618^{* *}$ & .004 \\
Private Expenditures & $.2412^{* *}$ & .027 & $.4965^{* *}$ & .036 \\
Interest Rate & $-.0035^{*}$ & .068 & $-.0065^{*}$ & .084 \\
$\begin{array}{l}\text { Public Expenditures } \\
\quad\end{array}$ & & & & \\
$\quad$ On Education & $7.342^{* *}$ & .001 & $3.625^{* *}$ & .019 \\
Root Mean Square Error & & & & \\
Adjusted R-squared & 1.396 & & 1.576 & \\
p-value for the model significance: & .6292 & .000 & .703 & \\
Number of observations: & 173 & & .000 & \\
p-value for White test: & .624 & & .573 & \\
p-value for the LM test: & .501 & & .485 & \\
p-value for RESET on omitted variables: & .539 & & .601 & \\
\hline
\end{tabular}

Note: ${ }^{*}$ and ${ }^{* *}$ denotes significant levels at $10 \%$ and $5 \%$, respectively.

Although this research is on China, the result could be applied to analyze other transitional economies as well. Future research can investigate the effect of vocational education on other sectors of the economy when data become available or compare and contrast this effect among different provinces and autonomous regions in China. 


\section{References}

Arellano, M. \& Bond, S. (1991). Some Test of Specification for Panel Data: Monte Carlo Evidence and an Application for Employment Equations. The Review of Economic Studies, 58 (2), 277-297.

Banerji, A., Cunningham, W., Fiszbein, A., King E., Patrinos H., Robalino, D. \& Tan J. (2010). Stepping up Skills for More Jobs and Higher Productivity. World Bank Web Site, www.worldbank.org/humandevelopment/skillsforjobs.

Bils, M. \& Klenow, J. P. (2000). Does Schooling Cause Growth? American Economic Review, 90, 1160-1183.

Blundell, R. \& Bond, S. (1998). Initial conditions and moment restrictions in dynamic panel data models. Journal of Econometrics, 87, 11-143.

Bond, S. (2002). Dynamic panel data models: A guide to micro data methods and practice. CEMMAP working paper; CWP09/, 02.

Caselli, F., Esquivel, G. \& Lefort, F. (1996). Reopening the convergence debate: a new look at cross-country empirics. Journal of Economic Growth 1, 363-389.

Chen, B. \& Feng, Y. (2000). Determinant of Economic Growth in China: Private Enterprise, Education, and Openness. China Economic Review, 11(1), 1-15.

Demuger, S. (2001). Infrastructure and Economic Growth: an Explanation for Regional Disparities in China. Journal of Comparative Economics, 29, 95-117.

Fleisher, B., Hu, Y. \& Haizheng, L. (2006). Economic Transition, Higher Education, and Worker Productivity in China. Working paper (submitted), Department of Economic, Ohio State University.

Hojo, M. (2003). An in direct effect of education on growth. Economics Letters, 80, 31-34.

Hua, P. (2006). How education influences productivity growth? Evidence from the Chinese provinces. Working paper, CERDI-INDIRECT, CNRS-University d' Auvergne, 1-34.

Kumar, K. B. (2003). Education and Technology Adoption in a Small Open Economy: Theory and Evidence. Macroeconomic Dynamics, 7( 4), 586-617.

Islam, N. (1995). Growth empirics: a panel data approach. Quarterly Journal of Economics, 110, 1127 1170.

Jakubowski, M., Patrinos, H., Porta, E. \& Wisniewski, J. (2010). The impact of the 1999 education reform in Poland. World Bank Policy Research Working Paper, WPS 5263, 1-29.

Kennedy, P. (2006). A guide to econometrics, 6th edition. MIT Press, Cambridge, MA.

Masson, J. R. (2009). Vocational education and training and higher education in the transition countries. European journal of vocational training, 46, 89-113.

Vu, T. B. (2009). The Simultaneity in Human Capital Estimations: The Case of China. Chinese Business Review, 8, 25-53.

Vu, T. B. \& Hammes, D. (2007). Education and Productivity: A Three Stage Least Squares Estimation. The 10th International Conference for Business and Development, Kyoto, Japan, conference proceedings, 1023-1048. 